\title{
Dengue occurrence relations and serology: cross-sectional analysis of results from the Guerrero State, Mexico, baseline for a cluster-randomised controlled trial of community mobilisation for dengue prevention
}

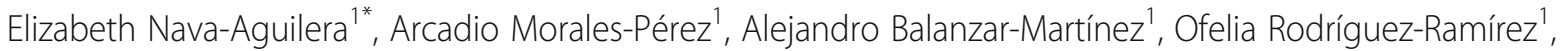
Abel Jiménez-Alejo ${ }^{1}$, Miguel Flores-Moreno ${ }^{1}$, David Gasga-Salinas ${ }^{1}$, José Legorreta-Soberanis ${ }^{1}$, Sergio Paredes-Solís ${ }^{1}$, Pedro Antonio Morales-Nava², María de Lourdes Soto-Ríos ${ }^{3}$, Robert J Ledogar ${ }^{4}$, Joséfina Coloma ${ }^{5}$, Eva Harris ${ }^{5}$ and Neil Andersson ${ }^{1,6}$

From The Camino Verde Trial colloquium

Acapulco, Mexico. 17-21 June 2013

\begin{abstract}
Background: The Mexican arm of the Camino Verde trial of community mobilisation for dengue prevention covered three coastal regions of Guerrero state: Acapulco, Costa Grande and Costa Chica. A baseline cross-sectional survey provided data for community mobilisation and for adapting the intervention design to concrete conditions in the intervention areas.

Methods: Trained field teams constructed community profiles in randomly selected clusters, based on observation and key informant interviews. In each household they carried out an entomological inspection of water containers, collected information on socio-demographic variables and cases of dengue illness among household members in the last year, and gathered paired saliva samples from children aged 3-9 years, which were subjected to ELISA testing to detect recent dengue infection. We examined associations with dengue illness and recent dengue infection in bivariate and then multivariate analysis.

(Continued on next page)
\end{abstract}

\footnotetext{
* Correspondence: enava@ciet.org

${ }^{1}$ Centro de Investigación de Enfermedades Tropicales (CIET), Universidad

Autónoma de Guerrero, Acapulco, Guerrero, Mexico

Full list of author information is available at the end of the article
} 
(Continued from previous page)

Results: In 70/90 clusters, key informants were unable to identify any organized community groups. Some $1.9 \%(1029 / 55,723)$ of the household population reported dengue illness in the past year, with a higher rate in Acapulco region. Among children 3-9 years old, 6.1\% (392/6382) had serological evidence of recent dengue infection. In all three regions, household use of anti-mosquito products, household heads working, and households having less than 5 members were associated with self-reported dengue illness. In Acapulco region, people aged less than 25 years, those with a more educated household head and those from urban sites were also more likely to report dengue illness, while in Costa Chica and Costa Grande, females were more likely to report dengue illness. Among children aged 3-9 years, those aged 3-4 years and those living in Acapulco were more likely to have evidence of recent dengue infection.

Conclusions: The evidence from the baseline survey provided important support for the design and implementation of the trial intervention. The weakness of community leadership and the relatively low rates of self-reported dengue illness were challenges that the Mexican intervention team had to overcome. The higher dengue illness occurrence among women in Costa Grande and Costa Chica may help explain why women participated more than men in activities during the Camino Verde trial.

Keywords: Dengue, Infection, Serology, Risk factors

\section{Background}

Throughout the first decade of the twenty-first century, dengue fever (DF) was a major public health concern. In Mexico as a whole, DF rates increased almost tenfold from 5018 registered cases in 2003, to 48,456 cases in 2007 [1], with a similar trend in the Mexican state of Guerrero. In 2012, Guerrero registered one of the highest DF incidence rates in the country (113 per 100,000), and the fourth highest rate for dengue hemorrhagic fever (DHF) [1]. More recently, dengue has continued to be a public health concern. In 2015, 26,665 cases of DF were reported in Mexico. Of these, 5464 were cases of DHF which resulted in 42 deaths [2]. Guerrero, which comprises $2.9 \%$ of the total national population [3], reported $6.5 \%$ of DF cases, $9.5 \%$ of DHF cases, and one out of four dengue-related fatalities in the country.

Most dengue infections are asymptomatic or present as a non-specific feverish illness, with asymptomatic infections predominating [4-6]. Authors have linked the spread of DF in the Americas to demographic, environmental and biological factors; social changes; the presence of Aedes aegypti breeding sites; and deficient public service infrastructure [7-9]. A task as complex as decreasing the spread of dengue requires an integrated approach, with involvement of households and communities as well as public services $[10,11]$. The Camino Verde cluster randomised controlled trial (CRCT) in Mexico and Nicaragua (2010-2012) aimed to test the added value of community mobilisation for dengue prevention $[12,13]$.

This article reports on findings from the 2010 baseline survey for the Mexican arm of the Camino Verde trial, which took place in the three coastal regions of Guerrero State $[12,13]$. The baseline surveys in Mexico and Nicaragua were not carried out to serve as points of reference for measuring impact of the interventions. Rather, they provided important data used at the beginning of the trial and during the intervention: for stratifying the random allocation of the sample into intervention and reference communities; for input into the evidencebased community mobilisation; and for adapting the intervention implementation to local conditions in the trial communities. The baseline findings reported here are also useful for interpreting the Camino Verde trial results and evaluating their implications for future action against dengue in Guerrero state, in Mexico as a whole, and elsewhere.

\section{Methods}

The methods of the Camino Verde trial, including the conduct of the baseline surveys, are described in detail elsewhere [12, 13]. A brief description follows here. The Mexican arm of trial took place in a random sample of 90 clusters in the three coastal regions of Guerrero State (Acapulco, Costa Grande and Costa Chica) drawn from the State Health Secretariat's register of census enumeration areas. Each cluster comprised on average 137 contiguous households. The baseline survey included: a household questionnaire covering demographics and socio-economic status, and self-reported dengue illness in family members during the last 12 months; an entomological survey in the same households examining water containers for Aedes aegypti larvae and pupae and the presence of temephos (a larvicidal chemical added to household water containers as a key part of the government vector control programme for dengue prevention); paired saliva samples from children aged 3-9 years in the households to test for dengue-specific IgG antibodies at the beginning and end of the three-month dengue 
season; and interviews with key informants (anyone with a good knowledge about the community) in each cluster which supported construction of a community profile. The survey instruments drew on experience from a pilot study in Nicaragua [14], and trained local fieldworkers carried out the interviews and entomological inspections, and obtained the saliva samples. They obtained consent to work in the communities from local leaders and sought oral informed consent in each household.

\section{Measurement of dengue antibodies}

We used an ELISA procedure for detecting dengue-specific IgG antibodies in the paired saliva samples $[15,16]$. We used dedicated software for automatic optical density transfer from the ELISA reader to the computer, and used the same programme to estimate IgG units, to estimate if there was recent dengue infection or not, and to check for data concordance [17].

\section{Data management and analysis}

Trained operators entered data twice using Epi-Data software [18], with validation to minimize keystroke errors. Analysis relied on CIETmap open-source software [19], which provides a user-friendly interface with the R statistical programming language [20]. We examined associations with two dengue outcomes: self-reported cases of dengue illness in any household member in the last 12 months; and recent dengue infection among children aged 3-9 years, as evidenced by a doubling of specific dengue-specific IgG between the paired saliva samples. We examined associations between these outcomes and individual, household and community-level factors, first in bivariate analysis and then in multivariate analysis, using the Mantel-Haenszel procedure [21] with adjustment for clustering [22]. For multivariate analysis, we began with saturated models including variables associated with the outcome in bivariate analysis and performed step-wise deletion of the least significant association until all the remaining variables were significantly associated with the outcome at the $5 \%$ level. We tested for effect modification using Woolf's $x^{2}$ test for heterogeneity [23]. We express associations as the odds ratio (OR) and cluster-adjusted 95\% confidence intervals ( $95 \%$ CIca).

\section{Results}

The field teams visited 12,399 homes in 90 clusters and collected information from 54,728 people; $81.2 \%$ $(10,067 / 12,399)$ of respondents were women. Of 7048 children aged 3-9 years who provided the first saliva sample, 90.6\% (6382/7048) provided a second sample. The loss to follow up was mainly due to families moving away from the area. Entomological inspections collected data from 45,013 water containers located inside or next to visited households.

\section{Characteristics of the communities and sample population}

Table 1 shows characteristics of the communities. Few communities, especially in Costa Chica and Costa Grande regions, had a household drainage system or paved streets. Many had ditches or ravines where stagnant water could accumulate, and these were often blocked. Over half the communities had tap water inside the households (57/90). Most communities (68/90) had a water supply system: from a local source in 40 , a municipal network in 28 , and wells in 14 . Only 43 had a regular water supply, the irregular supply forcing households to store water. The main sources of water when the piped supply failed were wells, water storage tanks and rivers. About half the communities had a waste collection system, though not always regular. In most of the communities, the key informants interviewed did not identify any organized community groups.

\section{Socio-demographic data}

The mean number of people per household was 4.4 (range $1-24$, SD 2.2). Some 53\% (28,458/54,728) of household members were female, with a mean age of 28.4 years (range 0-90 years, SD 21.05). Nearly all households $(90.9 \% ; 11,265 / 12,396)$ spoke Spanish at home with a few reporting other languages, including Nomnda, Me'pha, Nuu savi, Náhuatl, and English. Similarly, 96\% (11,900/ 12,396) of households reported Spanish as their preferred language for receiving health information. Some $40 \%$ $(5041 / 12,399)$ of household heads had no education or did not finish primary school, 20.9\% (2588/ 12,399) had completed primary education. The most frequent occupations of household heads were: farmer, 34.5\% (4280/ 12,399); housewife, 9.5\% (1184); merchant, 8.2\% (1021); private employee, $7.2 \%$ (891); bricklayer or laborer, $6.8 \%$ (838); and driver or machine operator, $5.1 \%$ (637). Some $6.2 \%$ (772) were reported to be unemployed.

Nearly all the dwellings were used as households (94.5\%; 11,720/ 12,399). About half the dwellings were of permanent construction (43.7\%; 5424/ 12,399); 41.5\% (5151) were semi-permanent, and a few were temporary $(14.2 \% ; 1762 / 12,399)$.

\section{Dengue illness}

Across all three regions, 1.9\% $(1029 / 55,723)$ of household members were reported to have had dengue illness in the last 12 months. This ranged from 3.5\% (663/ $19,174)$ in Acapulco region, through $1.5 \%(255 / 17,126)$ in Costa Grande, to $0.6 \%(111 / 18,423)$ in Costa Chica. One community in Acapulco region had a rate of $8.5 \%$ $(55 / 648)$.

Self-reported dengue illness was more common among youth. The age groups with the highest rates were: 1519 years, $2.9 \%$ (183/ 6419); $10-14$ years, $2.6 \%$ (176/6.670); 
Table 1 Profile of the 90 baseline survey clusters, stratified by region

\begin{tabular}{|c|c|c|c|c|}
\hline Features & Acapulco $n=30$ & Costa Grande $n=30$ & Costa Chica $n=30$ & Total $n=90$ \\
\hline Drainage at households & 16 & 7 & 8 & 31 \\
\hline Paved streets & 11 & 2 & 1 & 14 \\
\hline Ditches or ravines present & 27 & 28 & 27 & 82 \\
\hline Blocked ditches & 16 & 8 & 12 & 36 \\
\hline Mean no. empty lots (range) & $21.2(0-85)$ & $23.3(0-96)$ & $20.0(0-96)$ & $21.4(0-96)$ \\
\hline Uninhabited homes & 18 & 21 & 9 & 48 \\
\hline Health center present & 12 & 23 & 18 & 53 \\
\hline Tap water to households & 19 & 17 & 21 & 57 \\
\hline Local water system & 24 & 20 & 24 & 68 \\
\hline Regular water supply & 7 & 16 & 20 & 43 \\
\hline Alternative source if supply fails_- well or water storage tank & 14 & 13 & 14 & 41 \\
\hline Garbage collection service & 25 & 16 & 9 & 50 \\
\hline Regular garbage collection service & 15 & 9 & 6 & 30 \\
\hline Garbage collection frequency: every three days & 3 & 1 & 2 & 6 \\
\hline Adequate collection service & 13 & 6 & 4 & 23 \\
\hline Organized groups ${ }^{a}$ & 8 & 5 & 7 & 20 \\
\hline
\end{tabular}

${ }^{a}$ Taxi drivers, Alcoholics Anonymous, Oportunidades groups, religious/social/political groups

5-9 years, 2.3\% (131/5.677); 20-24 years, 2.2\% (103/ 4599). Just over half the dengue illness cases were female (52.6\%; 488/1029). Among children aged 3-9 years, 2.1\% (163/7808) were reported to have had dengue illness in the last 12 months.

Table 2 shows bivariate analysis of factors potentially linked to self-reported dengue illness. Individuals were more likely to have had dengue illness if they were younger than 25 years, if they lived in an urban area, if they lived in Acapulco region, if their household was of permanent construction, if temephos had been placed in their household water containers within the last 3 months, if the household head had six years of education or more, if the household had less than five members, and if the household head was working (See Table 2).

Region was an effect modifier in the multivariate analysis of variables associated with dengue illness in the last year. We therefore constructed two models: one for Acapulco region, and another one for the Costa Grande and Costa Chica regions. Table 3 shows the final multivariate models. In the Acapulco region (Table 3a), factors associated with self-reported dengue illness in the last 12 months were: being younger than 25 years of age; having a household head who was working; having a household head with at least six years of education; having less than five people in the household; using antimosquito products in the household; and living in an urban site. In Costa Grande and Costa Chica (Table 3b), those more likely to report dengue illness in the last 12 months: were female; had a working household head; came from a household of less than 5 people; and came from a household that used anti-mosquito products.

\section{Recent dengue infection among children}

Across all three regions, 6.1\% (392/6382) of children aged 3-9 years had evidence of recent dengue infection (based on quadrupling of dengue-specific IgG antibody levels between paired saliva samples); 9\% (576/6382) based on trebling of IgG levels; and 17\% (1083/6382) based on doubling of IgG levels. The rate of recent infection was higher in Acapulco than in Costa Grande and Costa Chica. (Table 4).

As shown in Table 5, the proportions of children with evidence of recent dengue infection were higher among children aged 3-4 years than among older children. The rates of reported dengue illness among children were much lower than the rates of serological dengue infection (Table 5). In contrast to the age pattern for serological dengue infection, the proportions of children reported to have had dengue illness in the last 12 months were higher among children aged 8 and 9 years than among younger children (Table 5).

Bivariate analysis found evidence of factors linked to recent infection: being aged 3-4 years; living in an urban area; and living in the Acapulco region (Table 6).

Table 7 shows the final model from multivariate analysis of factors associated with recent dengue infection. Children aged 3-9 years old were more likely to have evidence of recent dengue infection if they were younger (aged 3-4 years), and if they lived in the Acapulco region. 
Table 2 Bivariate analysis of associations with reported dengue illness in the last 12 months in 53,641 household members

\begin{tabular}{|c|c|c|c|c|c|c|c|}
\hline \multirow[t]{2}{*}{ Variable } & \multirow[t]{2}{*}{ Levels } & \multicolumn{2}{|c|}{ With dengue } & \multicolumn{2}{|c|}{ No dengue } & \multirow[t]{2}{*}{ OR } & \multirow[t]{2}{*}{$95 \% \mathrm{Clca}$} \\
\hline & & Number & Percent & Number & Percent & & \\
\hline \multirow[t]{2}{*}{ Age } & $<25$ years & 649 & 2.3 & 28,025 & 97.7 & 1.56 & $1.32-1.85$ \\
\hline & $\geq 25$ years & 380 & 1.5 & 25,612 & 98.5 & & \\
\hline \multirow[t]{2}{*}{ Sex } & Male & 488 & 1.9 & 25,747 & 98.1 & 0.98 & $0.86-1.11$ \\
\hline & Female & 541 & 1.9 & 27,889 & 98.1 & & \\
\hline \multirow[t]{2}{*}{ Area of residence } & Urban & 650 & 2.6 & 24,060 & 97.4 & 2.1 & $1.46-3.04$ \\
\hline & Rural & 379 & 1.3 & 29,581 & 98.7 & & \\
\hline \multirow[t]{2}{*}{ Region } & Acapulco & 663 & 3.5 & 18,481 & 96.5 & 3.5 & $2.52-4.70$ \\
\hline & Costa Grande \& Costa Chica & 366 & 1.0 & 35,160 & 99.0 & & \\
\hline \multirow[t]{2}{*}{ Use of household } & Business/ home business & 63 & 2.4 & 2558 & 97.6 & 1.31 & $0.92-1.85$ \\
\hline & Home & 961 & 1.8 & 50,987 & 98.2 & & \\
\hline \multirow[t]{2}{*}{ Type of dwelling } & Permanent & 568 & 2.5 & 22,528 & 97.5 & 1.73 & $1.34-2.23$ \\
\hline & Semi-permanent/temporary & 449 & 1.4 & 30,820 & 98.6 & & \\
\hline \multirow[t]{2}{*}{ Temephos placed in water within last $3 \mathrm{~m}$} & Yes & 689 & 2.2 & 31,013 & 97.8 & 1.52 & $1.14-2.02$ \\
\hline & No & 308 & 1.4 & 21,082 & 98.6 & & \\
\hline \multirow[t]{2}{*}{ Household use of anti-mosquito products } & Yes & 587 & 2.4 & 23,717 & 97.6 & 1.69 & $1.40-2.04$ \\
\hline & No & 435 & 1.4 & 29,717 & 98.6 & & \\
\hline \multirow[t]{2}{*}{ Education of household head } & $\geq 6$ years of education & 718 & 2.2 & 31,819 & 97.8 & 1.64 & $1.32-2.05$ \\
\hline & $<6$ years or no education & 294 & 1.4 & 21,367 & 98.6 & & \\
\hline \multirow[t]{2}{*}{ Working household head } & Yes & 902 & 2.0 & 44,950 & 98.0 & 1.39 & $1.09-1.76$ \\
\hline & No & 118 & 1.4 & 8148 & 98.6 & & \\
\hline \multirow[t]{2}{*}{ Language } & Indigenous language & 31 & 0.8 & 3843 & 99.2 & 0.45 & $0.26-0.79$ \\
\hline & Spanish & 790 & 1.8 & 44,276 & 98.2 & & \\
\hline \multirow[t]{2}{*}{ People per household } & $<5$ people & 483 & 2.4 & 19,887 & 97.6 & 1.50 & $1.25-1.80$ \\
\hline & $\geq 5$ people & 546 & 1.6 & 33,753 & 98.4 & & \\
\hline \multirow[t]{2}{*}{ Larvae-positive containers } & Yes & 138 & 1.6 & 8316 & 98.4 & 0.84 & $0.68-1.05$ \\
\hline & No & 891 & 1.9 & 45,325 & 98.1 & & \\
\hline \multirow[t]{2}{*}{ Pupae-positive containers } & Yes & 73 & 1.5 & 4746 & 98.5 & 0.79 & $0.61-1.01$ \\
\hline & No & 956 & 1.9 & 48,895 & 98.1 & & \\
\hline \multirow[t]{2}{*}{ Containers positive for larvae/pupae } & Yes & 141 & 1.6 & 8470 & 98.4 & 0.85 & $0.68-1.05$ \\
\hline & No & 888 & 1.9 & 45,171 & 98.1 & & \\
\hline
\end{tabular}

OR Odds ratio, $95 \%$ Clca cluster adjusted $95 \%$ confidence interval

Figures in bold font indicate an association significant at the $5 \%$ level

\section{Discussion}

The survey which generated the findings reported here took place at the baseline of the Camino Verde trial [12, 13], before communities were randomised to intervention or control status. We used the findings about rates of dengue infection in different clusters to stratify the clusters prior to randomisation $[12,13]$. The findings shed light on the conditions under which the Camino Verde intervention took place in the coastal regions of Guerrero, Mexico, and supported the management of the intervention there [24].

Evidence was the main tool for community mobilisation in Camino Verde and results from the baseline survey were an important part of that evidence. The field teams shared three kinds of results from the baseline communities: those from the collection of children's saliva samples, those from the entomological inspections, and those from the household survey. Feedback of individual results from the saliva sample provided the opportunity for the brigadistas (community mobilisers) to approach every family in the community whose child provided two saliva samples during the baseline survey. In many cases it was the brigadista's first contact with the household and it provided a natural opportunity to discuss dengue, the Aedes aegypti mosquito and its behavior [24]. Evidence from the entomological inspection, reported elsewhere [25], showed the 
Table 3 Final models of multivariate analysis of factors associated with reported dengue illness in the last 12 months in household members

\begin{tabular}{|c|c|c|c|}
\hline Variable & Crude OR & adjusted OR & $95 \% \mathrm{Clca}$ \\
\hline \multicolumn{4}{|c|}{ a) Acapulco region, $N=19,008$, Clustered by site, $n=30$} \\
\hline Younger than 25 years & 2.09 & 2.23 & $1.67-2.98$ \\
\hline Working household head & 1.57 & 1.40 & $1.03-1.89$ \\
\hline Household head with $\geq 6$ years of education & 1.53 & 1.25 & $1.02-1.54$ \\
\hline$<5$ people in household & 1.45 & 1.59 & $1.25-2.02$ \\
\hline Household uses anti-mosquito products & 1.35 & 1.33 & $1.06-1.66$ \\
\hline Urban residence & 1.54 & 1.54 & $1.07-2.22$ \\
\hline \multicolumn{4}{|c|}{ b) Costa Grande and Costa Chica regions; $N=35,461$; Clustered by site, $n=60$} \\
\hline Female & 1.27 & 1.28 & $1.04-1.57$ \\
\hline Working household head & 1.45 & 1.54 & $1.11-2.12$ \\
\hline$<5$ people in household & 1.50 & 1.53 & $1.14-2.05$ \\
\hline Household uses anti-mosquito products & 1.69 & 1.68 & $1.22-2.32$ \\
\hline
\end{tabular}

For Acapulco region, other variables included in initial model were: sex, type of dwelling, presence of temephos, language, and presence of containers with larvae/pupae

For Costa Grande and Costa Chica regions, other variables included in initial model were: age, area of residence, type of dwelling, presence of temephos, education of household head, language, and presence of containers with larvae/pupae

types of containers where Aedes aegypti larvae and pupae were most concentrated, enabling the intervention team to prioritise these containers in their education efforts.

\section{Community organisation}

As reported here, community key informants in the baseline survey in Mexico could not identify any organized community groups in three-quarters of the 90 sites (see Table 1). This was in sharp contrast with Nicaragua where most neighborhoods had recognized, active leadership closely allied with the Sandinista government. The Mexican intervention team had to spend considerable time and effort in search of suitable community leadership before the intervention could be fully launched [24].

\section{Community priorities}

Levels of self-reported (that is, recognized) cases of dengue illness in the last 12 months were relatively low in the baseline survey in the 90 coastal clusters in Mexico: overall 1.9\%, and lower in Costa Grande and Costa Chica. The rate of dengue illness in Acapulco was
2.3 times higher (3.5/1.5) than in Costa Grande, and almost six times higher (3.5/0.6) than in Costa Chica. In the baseline survey in Managua, Nicaragua, self-reported dengue cases were $24 \%$ higher and serological recent infection was double compared to Mexico [12]. The low levels of recognized clinical dengue infection in the trial population in Mexico, especially in areas outside the Acapulco region (and Acapulco City itself), meant that the brigadistas sometimes faced communities that had priorities other than dengue and were therefore less interested in getting involved in activities to reduce mosquitoes in their environment.

In the Mexican baseline study reported here, urban residence was associated with both self-reported dengue illness and serological recent dengue infection. Other authors have reported that dengue is a mainly urban phenomenon, with infection risk higher where there is disorganized urban growth, with lack of access to water, electricity, drainage, paved streets, education and health services [26]. Such conditions exist in Acapulco, which is not only a tourist attraction, but also a destination for

Table 4 Recent dengue infection in children aged 3-9 years, by region

\begin{tabular}{lllllll}
\hline Region & \multicolumn{2}{l}{ Percentage (proportion) with evidence of recent dengue infection } & & \\
\cline { 2 - 7 } & Quadrupling of lgG level & $95 \% \mathrm{Cl}$ & Trebling of lgG level & $95 \% \mathrm{Cl}$ & Doubling of lgG level & $95 \% \mathrm{Cl}$ \\
\hline Acapulco $^{\mathrm{a}}$ & $9.2 \%(184 / 1994)$ & $8.0-10.6$ & $12.1 \%(242 / 1994)$ & $10.7-13.6$ & $19.4 \%(387 / 1994)$ & $17.7-21.2$ \\
Costa Grande $^{\mathrm{b}}$ & $5.2 \%(97 / 1869)$ & $4.2-6.3$ & $8.2 \%(153 / 1869)$ & $7.0-9.5$ & $16.5 \%(308 / 1869)$ & $14.8-18.3$ \\
Costa Chica $^{\mathrm{b}}$ & $4.4 \%(111 / 2519)$ & $3-6-5.3$ & $7.2 \%(181 / 2519)$ & $6.2-8.2$ & $15.4 \%(388 / 2519)$ & $14.0-16.9$ \\
Total & $6.1 \%(392 / 6382)$ & $5.6-6.8$ & $9.0 \%(576 / 6382)$ & $8.3-9.7$ & $17.0 \%(1083 / 6382)$ & $16.1-17.9$ \\
\hline
\end{tabular}

aPaired saliva samples in December 2009 and February 2010

baired saliva samples in May and November 2010 
Table 5 Recent dengue infection and reported dengue cases in last 12 months, in children aged 3-9 years, by age

\begin{tabular}{|c|c|c|c|c|c|}
\hline Age (years) & Number of children & Recent dengue infections ${ }^{a}$ & $\begin{array}{l}\text { Recent dengue infections } \\
\text { per } 1000 \text { children }\end{array}$ & $\begin{array}{l}\text { Dengue illness in } \\
\text { last } 12 \text { months }\end{array}$ & $\begin{array}{l}\text { Dengue illness } \\
\text { per } 1000 \text { children }\end{array}$ \\
\hline 3 & 742 & 93 & 125.3 & 9 & 12.1 \\
\hline 4 & 894 & 92 & 102.9 & 15 & 16.8 \\
\hline 5 & 824 & 63 & 76.5 & 14 & 17.0 \\
\hline 6 & 953 & 82 & 86.0 & 18 & 18.9 \\
\hline 7 & 921 & 82 & 89.0 & 16 & 17.4 \\
\hline 8 & 1001 & 73 & 72.9 & 35 & 35.0 \\
\hline 9 & 991 & 86 & 86.8 & 28 & 28.3 \\
\hline Total & 6326 & 571 & 90.3 & 135 & 21.3 \\
\hline
\end{tabular}

aDoubling of level of dengue specific IgG in paired saliva samples

Table 6 Bivariate analysis of associations with recent dengue infection (doubling of IgG levels) among 6326 children aged 3-9 years

\begin{tabular}{|c|c|c|c|c|c|c|c|}
\hline \multirow[t]{2}{*}{ Variable } & \multirow[t]{2}{*}{ Level } & \multicolumn{2}{|c|}{ With doubling of lgG } & \multicolumn{2}{|c|}{ Without doubling of IgG } & \multirow[t]{2}{*}{ OR } & \multirow[t]{2}{*}{$95 \%$ Clca } \\
\hline & & Number & Percent & Number & Percent & & \\
\hline \multirow[t]{2}{*}{ Age } & $3-4$ years & 318 & 19.4 & 1636 & 80.6 & 1.26 & $1.10-1.43$ \\
\hline & $5-9$ years & 756 & 16.1 & 4690 & 83.9 & & \\
\hline \multirow[t]{2}{*}{ Sex } & Male & 568 & 17.6 & 3219 & 82.4 & 1.10 & $0.96-1.26$ \\
\hline & Female & 515 & 16.3 & 3161 & 83.7 & & \\
\hline \multirow[t]{2}{*}{ Area of residence } & Urban & 451 & 18.5 & 2442 & 81.5 & 1.19 & $1.02-1.38$ \\
\hline & Rural & 632 & 16.0 & 3940 & 84.0 & & \\
\hline \multirow[t]{2}{*}{ Region } & Acapulco & 387 & 19.4 & 1994 & 80.6 & 1.28 & $1.10-1.49$ \\
\hline & Costa Grande \& Costa Chica & 696 & 15.9 & 4388 & 84.1 & & \\
\hline \multirow[t]{2}{*}{ Household use } & Business/Home-business & 51 & 21.1 & 242 & 78.9 & 1.32 & $0.99-1.78$ \\
\hline & Home & 1027 & 16.8 & 6123 & 83.2 & & \\
\hline \multirow[t]{2}{*}{ Type of dwelling } & Permanent & 401 & 17.2 & 2332 & 82.8 & 1.03 & $0.91-1.17$ \\
\hline & Semi-permanent/ temporary & 672 & 16.8 & 4011 & 83.2 & & \\
\hline \multirow[t]{2}{*}{ Temephos placed in water within last $3 \mathrm{~m}$} & Yes & 602 & 17.5 & 2847 & 82.5 & 1.07 & $0.93-1.22$ \\
\hline & No & 458 & 16.5 & 2313 & 83.9 & & \\
\hline \multirow[t]{2}{*}{ Use of anti-mosquito products } & Yes & 500 & 18.1 & 2766 & 81.9 & 1.15 & $1.00-1.33$ \\
\hline & No & 579 & 16.1 & 3595 & 83.9 & & \\
\hline \multirow[t]{2}{*}{ Education } & $\geq 6$ years of schooling & 672 & 16.8 & 4010 & 83.2 & 0.96 & $0.84-1.08$ \\
\hline & $<6$ years or no schooling & 405 & 17.4 & 2327 & 82.6 & & \\
\hline \multirow[t]{2}{*}{ Working head of household } & Yes & 937 & 16.8 & 5563 & 83.2 & 0.96 & $0.77-1.19$ \\
\hline & No & 130 & 17.4 & 745 & 82.6 & & \\
\hline \multirow[t]{2}{*}{ People in household } & $<5$ persons & 267 & 16.9 & 1581 & 83.1 & 0.99 & $0.88-1.12$ \\
\hline & $\geq 5$ persons & 816 & 17.0 & 4801 & 83.0 & & \\
\hline \multirow[t]{2}{*}{ Larvae-positive containers } & Yes & 154 & 16.8 & 916 & 83.2 & 0.99 & $0.85-1.15$ \\
\hline & No & 929 & 17.0 & 5466 & 83.0 & & \\
\hline \multirow[t]{2}{*}{ Pupae-positive containers } & Yes & 89 & 17.1 & 521 & 82.9 & 1.01 & $0.80-1.27$ \\
\hline & No & 994 & 17.0 & 5861 & 83.0 & & \\
\hline \multirow[t]{2}{*}{ Larvae- and pupae-positive containers } & Yes & 159 & 17.1 & 931 & 82.9 & 1.01 & $0.86-1.18$ \\
\hline & No & 924 & 17.0 & 5451 & 83.0 & & \\
\hline
\end{tabular}


Table 7 Final model of multivariate analysis of factors associated with recent dengue infection (doubling of lgG levels) among children 3-9 years of age $n=6326$; Clustered by site, $n=90$

\begin{tabular}{llll}
\hline Variable & OR & adjusted OR & $95 \%$ Clca \\
\hline 3-4 years of age & 1.26 & 1.25 & $1.10-1.43$ \\
Living in the Acapulco region & 1.28 & 1.27 & $1.08-1.50$ \\
\hline
\end{tabular}

Other variable included in initial model was urban/rural residence

many people who travel from within the State and the rest of Mexico looking for work. Despite the higher rate of dengue in urban sites in the baseline survey, the Aedes aegypti vector was present in every rural site [25] and frequent visits of rural dwellers to urban areas could put them at risk of contracting dengue and set off epidemic outbreaks in rural areas, as has been observed elsewhere [27].

\section{Self-reported dengue illness and dengue infection}

The rates of recognized dengue illness in the baseline survey were well below the rates of dengue infection (as assessed by IgG levels in saliva) in children aged 39 years (see Table 5). It is recognized that many cases of dengue infection are not associated with clinical dengue illness [6]. The findings from the saliva examinations in children provided parents with evidence of how the infection could be affecting their children, even in the absence of obvious illness at the time.

Subclinical infections are important. They may contribute to continuing dengue transmission, as well as to the emergence of serious forms of the illness. According to illness surveillance reports, strands DENV1 and DENV2 were present in Guerrero in 2009, while DENV1 and DENV3 were identified in 2010 [1, 2]. Previous studies show that co-circulation of DENV strands increases the risk of epidemics and serious dengue cases [28].

\section{Age patterns}

The incidence of self-reported dengue illness was higher among family members younger than 25 years. Other authors have reported a similar age gradient, and it may be that older adults have developed some level of immunity, having been exposed to all four serotypes-and been infected by at least one of them-over a longer period of time [29].

Among children aged 3-9 years, the age pattern for serological dengue showed higher rates among the youngest children (aged 3-4 years), while the age pattern for recognized dengue infection showed higher rates among the older children (aged 8-9 years) (see Table 5). The association between young age and serological evidence of recent dengue infection remained in multivariate analysis (Table 7). The higher rate of recognized dengue cases among the older children may be because older children are better at reporting symptoms; among younger children parents may confuse dengue fever with other health problems, such as a respiratory infection. Sharing the findings from the saliva samples helped to sensitize parents about the high rate of dengue infections among young children, which may go unrecognized even if they cause some non-specific symptoms.

\section{Other associations with self-reported dengue illness}

Several factors in the baseline survey were associated with self-reported dengue illness among household members although not with serological dengue infection among children aged 3-9 years. In smaller (less than 5 people) households, households where the head was working, and households with a more educated head, the increased reporting of dengue cases may be because there is better recognition of cases of dengue illness. A study in Brazil reported an association between higher income and a higher risk of dengue haemorrhagic fever [30], and a study in Thailand reported a higher risk of dengue among more educated households [31].

\section{Anti-mosquito products}

Use of anti-mosquito products was associated with selfreported cases of dengue illness in all three regions. Cause and effect in such associations are difficult to determine in cross-sectional studies. In the Mexican system of dengue prevention and control, health workers visit households with a recognized case of dengue fever to place temephos in the water and fumigate in the area [32]; this may sensitize households and lead them to increase their use of anti-mosquito products. Additional analysis of the baseline study highlighted high amounts being spent by households in anti-mosquito products [33], and the Camino Verde intervention emphasized non-chemical methods of vector control.

\section{Sex}

Among children between 3 and 9 years old, boys were slightly more likely than girls to have evidence of recent dengue infection (Table 7), while in Costa Grande and Costa Chica self-reported dengue cases among all ages were more common among women (Table 3b). In the mainly rural Costa Grande and Costa Chica regions, customs are more traditional and women spend more time at home where they may be more exposed to the Aedes aegypti mosquito which prefers to breed in domestic settings. As it turned out, in Mexico women were much more active than men in community activities to reduce mosquitoes during the Camino Verde trial [34]; one reason for their greater involvement may be that they perceived themselves as more affected by dengue. 


\section{Limitations}

We identified cases of dengue on the basis of self-reports from the household respondent in each household. Such reports may not be fully reliable. Under-reporting of dengue cases may have been more marked in some households, as discussed above. We did not ask about the severity of symptoms, although we did collect information about whether cases had been admitted to hospital for treatment [35]. As with all cross-sectional analyses, we cannot interpret the associations we identified in our analysis as being causal.

\section{Conclusions}

Findings from the baseline study of the Camino Verde trial confirmed and highlighted associations with dengue virus infection and with self-reported dengue illness. Discussion and dissemination of evidence from the baseline survey were integral to the intervention in the trial communities. The weakness of community leadership and the relatively low rates of self-reported dengue illness were challenges that the Mexican intervention team had to overcome. The higher occurrence of dengue illness among women in Costa Grande and Costa Chica noted in the baseline study may help explain why women participated more than men in achieving the successful outcome of the Camino Verde trial.

\section{Abbreviations}

95\% Cl: 95\% confidence interval; 95\% Clca: Cluster adjusted 95\% confidence interval; DENV: Dengue virus; DF: Dengue fever; DHF: Dengue hemorrhagic fever; ELISA: Enzyme-linked Immunosorbent assay; IgG: Immunoglobulin G; OR: Odds ratio

\section{Acknowledgments}

The authors thank Francisco Laucirica who translated the original Spanish draft into English.

\section{Funding}

The Camino Verde trial and this publication were funded by the UBS Optimus Foundation. Fomix-CONACYT-GUERRERO supported the work in Acapulco (Grant Number 2008-02-108541).

\section{Availability of data and materials}

No additional data available.

\section{Authors' contributions}

ENA was co-investigator of the Camino Verde trial and wrote the Spanish draft of this article; AMP led the field work during the Camino Verde intervention, analyzed saliva samples, assisted with data analysis and made significant contributions to the Spanish draft; ORR and AJA analyzed saliva samples; ABM, MFM, DGS, JLS, SPS, PAMN, MLSR, JC and EH made significant contributions to the Spanish draft; RJL edited the translation and made significant contributions to the final manuscript. NA, the principal investigator for the Camino Verde trial, made significant contributions to the final manuscript. All authors read and approved the final manuscript.

\section{Competing interests}

The authors declare that they have no competing interests.

\section{Ethics approval and consent to participate}

The study protocol was approved by the Research Ethics Board of CIETcanada (which had received the resources for the study) on 16 November 2009 and the Ethics Committee of the Centro de Investigación de Enfermedades Tropicales (CIET) at the Autonomous University of Guerrero on 27 November 2009. Local authorities and community leaders gave their consent for the study. We also asked every household for verbal consent to apply the survey questionnaire, collect saliva samples and perform entomological inspections.

\section{About this supplement}

This article has been published as part of BMC Public Health Volume 17 Supplement 1, 2017: The Green Way to Aedes aegypti mosquito control: aspects and implications of the Camino Verde trial in Mexico and Nicaragua. The full contents of the supplement are available online at https:// bmcpublichealth.biomedcentral.com/articles/supplements/volume-17supplement-1.

\section{Publisher's Note}

Springer Nature remains neutral with regard to jurisdictional claims in published maps and institutional affiliations.

\section{Author details}

${ }^{1}$ Centro de Investigación de Enfermedades Tropicales (CIET), Universidad Autónoma de Guerrero, Acapulco, Guerrero, Mexico. ²Facultad de Medicina, Universidad Autónoma de Guerrero, Taxco, Guerrero, Mexico. ${ }^{3}$ Escuela de Enfermería Número 4, Universidad Autónoma de Guerrero, Taxco, Guerrero, Mexico. ${ }^{4}$ CIETinternational, New York, USA. ${ }^{5}$ Division of Infectious Diseases and Vaccinology, School of Public Health, University of California, Berkeley, CA, USA. ${ }^{6}$ Department of Family Medicine, McGill University, Montreal, Canada.

Published: 30 May 2017

\section{References}

1. Secretaría de Salud. Centro Nacional de Vigilancia Epidemiológica y Control de Enfermedades. Panorama Epidemiológico del dengue y dengue hemorrágico en entidades federativas. http://www.epidemiologia.salud.gob. mx/anuario/html/anuarios.html y http://www.cenaprece.salud.gob.mx/ descargas/pdf/dengue.pdf. Accessed 1 May 2017.

2. Secretaría de Salud. Centro Nacional de Vigilancia Epidemiológica y Control de Enfermedades. Panorama Epidemiológico del dengue y dengue hemorrágico en entidades federativas hasta la semana 52 del año 2015. Información disponible en: http://www.epidemiologia.salud.gob.mx/anuario/ 2015/casos/grupo/027.pdf. Accessed 28 Apr 2017.

3. Instituto Nacional de Estadística y Geografía. http://www.inegi.org.mx/est/ contenidos/espanol/sistemas/aee12/estatal/GRO/default.htm. Accessed 28 Apr 2017.

4. Porter KR, Beckett CG, Kosasih H, Tan RI, Alisjahbana B, Rudiman PI, et al. Epidemiology of dengue and dengue hemorrhagic fever in a cohort of adults living in Bandung, west java. Indonesia Am J Trop Med Hyg. 2005:72:60-6.

5. Balmaseda A, Standish K, Mercado JC, Matute JC, Tellez Y, Saborio S, et al. Trends in patterns of dengue transmission over four years in a pediatric cohort study in Nicaragua. J Infect Dis. 2010;201:5-14.

6. Endy TP, Anderson KB, Nisalak A, Yoon I-K, Green S, Rothman AL, et al. Determinants of inapparent and symptomatic dengue infection in a prospective study of primary school children in Kamphaeng Phet. Thailand PLoS Negl Trop Dis. 2011:5(3):e975.

7. Gómez-Dantés H, Ramsey-Willoquet J. Dengue in the Americas: challenges for prevention and control. Cad. Saúde Pública, Rio de Janeiro. 2009;25(Sup 1):S19-31

8. Koopman J, Prevots DR, Vaca MA, Gómez-Dantés H, Zarate-Aquino ML, Longini IM Jr, et al. Determinants and predictors of dengue infection in Mexico. Am J Epidemiol. 1991;133:1168-78.

9. Jury MR. Climate influence on dengue epidemics in Puerto Rico. Int J Environ Health Res. 2008;18:323-34

10. World Health Organization. Dengue: Guidelines for diagnosis, treatment, prevention and control. World Health Organization; 2009. http://www.who. int/tdr/publications/documents/dengue-diagnosis.pdf. Accessed 28 Apr 2017. 
11. World Health Organization. Dengue: control strategies. http://www.who.int/ denguecontrol/control_strategies/en/. Accessed 28 Apr 2017.

12. Andersson N, Nava-Aguilera E, Arosteguí J, Morales-Perez A, Suazo-Laguna $H$, Legorreta-Soberanis J, et al. Evidence based community mobilization for dengue prevention in Nicaragua and Mexico (Camino Verde, the Green way): cluster randomized controlled trial. BMJ. 2015;351:h3267.

13. Andersson N, Arostegui J, Nava-Aguilera E, Harris E, Ledogar RJ. Camino Verde (Green Way): Evidence-based community mobilisation for dengue control in Nicaragua and Mexico: feasibility study and study protocol for a randomised controlled trial. BMC Public Health. 2017;17(Suppl 1):S3.

14. Arostegui J, Suazo H, Coloma J, Carcamo C, Hernandez C, Balmaseda A, et al and the CIET Dengue Group-Nicaragua. Impact on serological, entomological, and behavioral indices of an evidence-based communityderived communication programme for the control of Aedes aegypti and dengue in Managua, Nicaragua. 57th Annual Meeting of the American Society of Tropical Medicine and Hygiene; 2008.

15. Kuno G, Gomez I, Gubler DJ. An ELISA procedure for the diagnosis of dengue infections. J Virol Methods. 1991;33:101-13.

16. Balmaseda A, Guzman MG, Hammond S, Robleto G, Flores C, Téllez Y, et al. Diagnosis of dengue virus infection by detection of specific immunoglobulin M (lgM) and IgA antibodies in serum and saliva. Clin Diagn Lab Immunol. 2003;10:317-22.

17. Avilés W, Ortega O, Kuan G, Coloma J, Harris E. Integration of information technologies in clinical studies in Nicaragua. PLoS Med. 2007;4:1578-83.

18. Lauritsen JM, Bruus M. EpiData (version 3). A comprehensive tool for validated entry and documentation of data. Odense: The EpiData Association; 2003-2008.

19. Andersson N, Mitchell S. Epidemiological geomatics in evaluation of mine risk education in Afghanistan: introducing population weighted raster maps. Int J Health Geogr. 2006;5:1.

20. R Core Team. R: A language and environment for statistical computing. Vienna: R Foundation for Statistical Computing; 2013. https://cran.r-project. org/doc/manuals/fullrefman.pdf. Accessed 28 Apr 2017.

21. Mantel N, Haenszel W. Statistical aspects of the analysis of data retrospective studies of disease. J Natl Cancer Inst. 1959;222:719-48.

22. Andersson N, Lamothe G. Clustering and meso-level variables in crosssectional surveys: an example of food aid during the Bosnian crisis. BMC Health Serv Res. 2011;11(Suppl 2):S15.

23. Woolf B. On estimating the relation between blood group and disease. Ann Hum Genet. 1955;19(4):251-3.

24. Morales-Pérez A, Nava-Aguilera E, Legorreta-Soberanis J, Paredes-Solís S, Balanzar-Martínez A, Serrano-de los Santos FR, et al. Which Green Way: description of the intervention for mobilising against Aedes aegypti under difficult security conditions in southern Mexico. BMC Public Health. 2017; 17(Suppl 1):S14.

25. Morales-Pérez A, Nava-Aguilera E, Balanzar-Martínez A, Cortés-Guzmán AJ, Gasga-Salinas D, Rodríguez-Ramos IE, et al. Aedes aegypti breeding ecology in Guerrero: cross-sectional study of mosquito breeding sites from the baseline for the Camino Verde trial in Mexico. BMC Public Health. 2017; 17(Suppl 1):S7.

26. Gubler DJ. Dengue, urbanization and globalization: the unholy trinity of the 21st century. Trop Med Health. 2011;4(s):3-11.

27. da Silva-Nunes M, de Souza VAF, Pannuti CS, Sperança MA, Terzian ACB, Nogueira ML, et al. Risk factors for dengue virus infection in rural Amazonia: population-based cross-sectional surveys. Am J Trop Med Hyg. 2008;79(4):485-94.

28. Khan E, Hasan R, Mehraj V, Nasir A, Siddiqui J, Hewson R. Co-circulations of two genotypes of dengue virus in 2006 out-break of dengue hemorrhagic fever in Karachi, Pakistan. J Clin Virol. 2008;43:176-9.

29. Koh BK, Ng LC, Kita Y, Tang CS, Ang LW, Wong KY, et al. The 2005 dengue epidemic in Singapore: epidemiology, prevention and control. Ann Acad Med Singap. 2008;37:538-45.

30. Figueiredo MA, Rodrigues LC, Barreto ML, Lima JW, Costa MC, Morato V, et al. Allergies and diabetes as risk factors for dengue hemorrhagic fever: results of the case control study. PLoS Negl Trop Dis. 2010;4:e699.

31. Koyadun S, Butraporn P, Kittayapong P. Ecological and sociodemographic risk determinants for dengue transmission in urban areas in Thailand. Interdiscip Perspect Infect Dis. 2012;2012:1-12.

32. Secretaría de Salud, Subsecretaría de Prevención y Promoción de la Salud. Programa de Acción Específico. Prevención y Control de Dengue 20132018. http://www.cenaprece.salud.gob.mx/descargas/pdf/PAE_ PrevencionControlDengue2013_2018.pdf. Accessed 28 Apr 2017.
33. Legorreta-Soberanis J, Paredes-Solís S, Morales-Pérez A, Nava-Aguilera E, Serrano-de los Santos FR, Sánchez-Gervacio BM, et al. Household costs for personal protection against mosquitoes: secondary outcomes from a randomised controlled trial of dengue prevention in Guerrero state, Mexico. BMC Public Health. 2017;17(Suppl 1):S17.

34. Andersson N, Beauchamp M, Nava-Aguilera E, Paredes-Solis S, Šajna M. The women made it work: fuzzy transitive closure of the results chain in a dengue prevention trial in Mexico. BMC Public Health. 2017;17(Suppl 1):S15.

35. Legorreta-Soberanis J, Paredes-Solís S, Morales-Pérez A, Nava-Aguilera E, Serrano-de los Santos FR, Dimas-Garcia DL, et al. Household costs of dengue illness: secondary outcomes from a randomised controlled trial of dengue prevention in Guerrero state, Mexico. BMC Public Health. 2017; 17(Suppl 1):S18

\section{Submit your next manuscript to BioMed Central and we will help you at every step:}

- We accept pre-submission inquiries

- Our selector tool helps you to find the most relevant journal

- We provide round the clock customer support

- Convenient online submission

- Thorough peer review

- Inclusion in PubMed and all major indexing services

- Maximum visibility for your research

Submit your manuscript at www.biomedcentral.com/submit
Biomed Central 